Article

\title{
Near-Infrared Fluorescence Detection of Acetylcholine in Aqueous Solution Using a Complex of Rhodamine 800 and p-Sulfonato-calix[8]arene
}

\section{Takashi Jin}

WPI Immunology Frontier Research Center, Osaka University, Yamada-oka, 1-3, Suita, Osaka 5650871, Japan; E-Mail: jin@fbs.osaka-u.ac.jp; Tel.: +81-6-6879-4427; Fax: +81-6-6879-4426

Received: 18 February 2010; in revised form: 4 March 2010 / Accepted: 9 March 2010 /

Published: 23 March 2010

\begin{abstract}
The complexing properties of $p$-sulfonatocalix[n] arenes $(\mathrm{n}=4: \mathrm{S}[4], \mathrm{n}=6$ : $\mathrm{S}[6]$, and $n=8: S[8])$ for rhodamine $800(\mathrm{Rh} 800)$ and indocyanine green (ICG) were examined to develop a near-infrared (NIR) fluorescence detection method for acetylcholine (ACh). We found that Rh800 (as a cation) forms an inclusion complex with S[n], while ICG (as a twitter ion) have no binding ability for $\mathrm{S}[\mathrm{n}]$. The binding ability of Rh800 to S[n] decreased in the order of S[8] > S[6] >> S[4]. By the formation of the complex between Rh800 and $\mathrm{S}[8]$, fluorescence intensity of the $\mathrm{Rh} 800$ was significantly decreased. From the fluorescence titration of Rh800 by S[8], stoichiometry of the Rh800-S[8] complex was determined to be $1: 1$ with a dissociation constant of $2.2 \mu \mathrm{M}$ in PBS. The addition of ACh to the aqueous solution of the Rh800-S[8] complex caused a fluorescence increase of $\mathrm{Rh} 800$, resulting from a competitive replacement of $\mathrm{Rh} 800$ by $\mathrm{ACh}$ in the complex. From the fluorescence change by the competitive fluorophore replacement, stoichiometry of the Rh800-ACh complex was found to be $1: 1$ with a dissociation constant of $1.7 \mathrm{mM}$. The effects of other neurotransmitters on the fluorescence spectra of the Rh800-S[8] complex were examined for dopamine, GABA, glycine, and L-asparatic acid. Among the neurotransmitters examined, fluorescence response of the Rh800-S[8] complex was highly specific to ACh. Rh800-S[8] complexes can be used as a NIR fluorescent probe for the detection of ACh $\left(5 \times 10^{-4}-10^{-3} \mathrm{M}\right)$ in PBS buffer $(\mathrm{pH}=7.2)$.
\end{abstract}

Keywords: near-infrared fluorescence; fluorescence detection; acetylcholine; dopamine; rhodamine 800 ; $p$-sulfonatocalixarene 


\section{Introduction}

Acetylcholine ( $\mathrm{ACh}$ ) is one of the most abundant neurotransmitters in the nervous system [1]. ACh acts as a transmitter at synapses in the ganglia of the visceral motor system, and at a variety of sites within the central nervous system. After the binding to ACh receptors at postsynaptic membranes, ACh is rapidly hydrolyzed to choline and acetic acids by ACh esterase to prevent over-accumulation of ACh. The concentration of ACh in the synaptic cleft of an active neuromuscular junction is about $5 \times 10^{-4} \mathrm{M}$ [2]. There are many methods for measuring the concentration of ACh: GC-MS [3] and HPLC with chemiluminescence assay [4,5], colorimetric assay [6], and radioimmunoassay [7,8]. Recently, electrochemical methods using ACh esterase-modified electrodes have been developed $[9,10]$. However, these methods involve some complicated and time-consuming procedures, and require expensive equipments. The objective of this work is to develop a facile fluorescence detection method for ACh in the near-infrared (NIR) region.

Compared to optical sensing using absorption, fluorescence sensing is simple and highly sensitive, because fluorescence intensity is measured directly without comparison with a reference [11]. By using a conventional spectrofluorometer, the concentration $(\mu \mathrm{M}-\mathrm{nM})$ of fluorescent molecules in aqueous solution can be easily determined. However, fluorescence sensing in biological samples has some complicated problem concerning light absorption and scattering. For example, in living tissues, there are many intrinsic chromophores like hemoproteins and flavin-containing proteins that absorb or emit visible light [11,12]. In contrast, NIR light ranging from $700 \mathrm{~nm}$ to $1100 \mathrm{~nm}$ is useful for in vivo fluorescence sensing. In living tissues, the absorption coefficient of NIR light is much lower than that of visible light, and the scattering of NIR light is much smaller than that of visible light $[13,14]$.

In this paper, we report a NIR fluorescence detection method for ACh using a complex of Rh800 and S[8]. So far, it has been shown that $\mathrm{S}[\mathrm{n}]$ have binding abilities for quaternary ammonium cations [15-19], and they are able to recognize ACh in aqueous solution [20-27]. Koh et al. first reported the utility of the complex of S[6] and a fluorescent ACh analog for the detection of ACh in aqueous solution [21]. Previously, we reported that S[8] strongly binds to fluorescent ACh analogs with cationic charges, dansylcholine [23] and rhodamine 6G [27] in aqueous solution, and their fluorescence can be used for the detection of $10^{-4} \mathrm{M}$ levels of ACh in aqueous solution. Recently, Korbakov et al. [26] have reported ACh detection at micromolar concentrations by use of the complex between a cationic fluorescent guest, trans-4-[4-(dimethylamino)styryl]-1-methylpyridium $p$ toluensulfonate with S[6]. All of these methods, however, are limited to fluorescence detection of ACh in the visible region. To the best of our knowledge, there are no reports of NIR fluorescent probes for detecting ACh in aqueous solutions.

To develop a NIR fluorescence detection method for ACh, we examined complexing properties of NIR fluorescent dyes (Rh800 and ICG) for S [n] in aqueous solution (Scheme 1). We found that Rh800 has a strong binding ability to $\mathrm{S}[8]$, while ICG shows no binding ability to $\mathrm{S}[\mathrm{n}]$. The formation of Rh800-S[n] complex and the competitive binding of ACh to Rh800-S[8] complex were examined by fluorescence titration experiments. The binding selectivity of the Rh800-S[8] complex was quite specific to ACh among other neurotransmitters such as dopamine, GABA, and glycine. We demonstrate the utility of Rh800-S[8] complex as a NIR fluorescent probe for determining ACh concentration $\left(5 \times 10^{-4}-10^{-3} \mathrm{M}\right)$ in aqueous solutions. 
Scheme 1. Molecular structure of the $p$-sulfonatocalix[n]arenes $(\mathrm{S}[\mathrm{n}])$ : acetylcholine (ACh), and the NIR-fluorescent dyes: rhodamine 800 (Rh800) and indocyanine green (ICG).

\section{p-Sulfonatocalix $[\mathbf{n}]$ arenes}

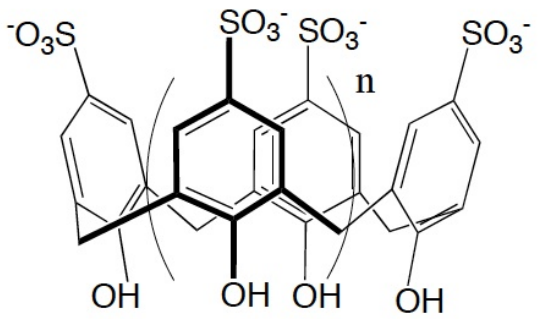

\section{Acetylcholine (ACh)}<smiles>CC(=O)OCC[N+](C)(C)C</smiles>

$\mathrm{S}[4](\mathrm{n}=1), \mathbf{S}[6](\mathrm{n}=3), \mathrm{S}[8](\mathrm{n}=5)$

\section{NIR fluorescent dyes}

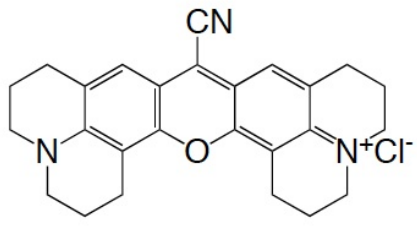

Rhodamine 800 (Rh800)

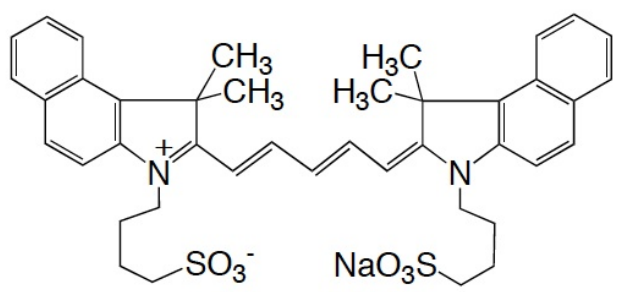

Indocyanine green (ICG)

\section{Results and Discussion}

\subsection{Fluorescence Properties of Rh800 and ICG}

We have chosen Rh800 and ICG as guest NIR fluorophores for S[n]. Rh800 is one of the few rhodamines that have NIR fluorescence, and it has been used as a laser dye [28]. Recently, Rh800 was also used as a mitochondrial membrane potential sensitive dye [29]. ICG is a most popular NIR dye and is used for medical diagnostics such as hepatic function, liver blood flow, and for ophthalmic angiography [30,31]. Rh800 has a cationic charge, and ICG has no net charge with a twitter ion (Scheme 1).

Figure 1 shows the emission and excitation spectra of Rh800 and ICG in PBS buffer. Rh800 emits at about $710 \mathrm{~nm}$ in PBS. ICG has an emission peak at about $800 \mathrm{~nm}$ and can be excited by NIR-light (circa700 nm-800 nm). It has been reported that fluorescence life times of Rh800 and ICG are less than $1 \mathrm{~ns}$ in aqueous solutions [32,33], and the fluorescence efficiency of these NIR-dyes is much lower than that of fluorescence dyes such as rhodamine 6G and fluorescein in the visible region [30]. Since there are no suitable quantum yield (QY) standards in the NIR region, we used an absolute QY 
measurement method (see, experimental section) for determining QYs of the NIR-dyes: $3.8 \%$ for $\mathrm{Rh} 800$ (in PBS) and $0.5 \%$ for ICG (in water).

Figure 1. Emission and excitation spectra of Rh800 (red lines) and ICG (blue lines) in PBS. Solid and dotted lines shows emission and excitation spectra, respectively. The concentration of the fluorescent dyes was $40 \mathrm{nM}$.

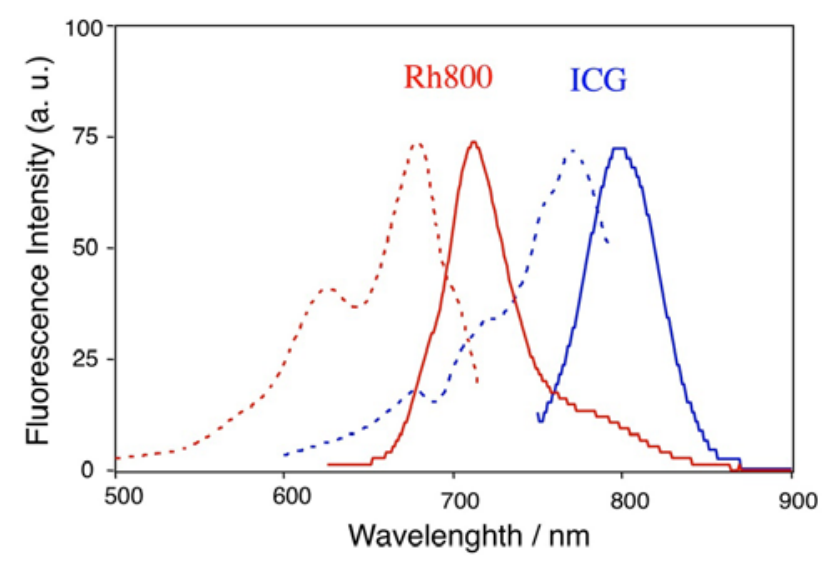

\subsection{The Complexing Abilities of Rh800 and ICG for S[n]}

To examine the complexing abilities of Rh800 and ICG, we measured their fluorescence spectra in the presence of S[n]. Since it is well known that S[8] strongly binds to rhodamine 6G [27] and rhodamine B [22], we first examined the effects of S[8] on the fluorescence spectra of Rh800 and ICG. (Figure 2). The fluorescence of Rh800 was quenched by S[8]. However, the fluorescence of Rh800 was not completely diminished even with the addition of excess amounts of S[8]. To gain insight for the quenching mechanism [34] for $\mathrm{Rh} 800$, we measured the temperature dependence of the fluorescence quenching by S[8]. The Stern-Volmer plots at $25{ }^{\circ} \mathrm{C}$ and $50{ }^{\circ} \mathrm{C}$ are shown as an inset in Figure 2a. It should be noted that Rh800 is quenched more effectively at lower temperature. This result indicates that the fluorescence quenching of $\mathrm{Rh} 800$ dose not result from the dynamic (collisional) interaction between Rh800 and S[8]. In the case of ICG, fluorescence changes were not observed by addition of S[8], indicating that ICG (as a twitter ion) has no binding ability to S[8]. This result is consistent with our previously reported result [23] that a cationic fluorescent ACh analog, dansylcholine binds to S[8], while a neutral fluorescent ACh analog, dansylsulfoamide does not bind to $\mathrm{S}[8]$.

Figure 3 shows changes in the relative fluorescence intensity of Rh800 upon adding S[n]. The fluorescence quenching of Rh800 by S[n] was significantly affected by the size of $S[n]$. Even at the presence of 1,300 equivalents of S[4], fluorescence intensity of the Rh800 was not changed. In contrast, the addition of S[6] and S[8] significantly quenched the fluorescence intensity of Rh800. The excess amounts of $\mathrm{S}[6]$ and $\mathrm{S}[8]$ decreased the fluorescence intensity of $\mathrm{Rh} 800$ by a factor of $40 \%$ and $70 \%$, respectively. This size dependency suggests that the quenching of $\mathrm{Rh} 800$ results from the static interaction (complex formation) between Rh800 and S[n], but not from the collisional interaction between Rh800 and S[n]. Assuming that Rh800 forms a 1:1 complex with $\mathrm{S}[\mathrm{n}]$, the dissociation 
constants $\left(K_{d}\right)$ of $\mathrm{Rh} 800-\mathrm{S}[\mathrm{n}]$ complex can be rationalized to the fluorescence intensity change $(\Delta F)$ in the presence of excess amounts of $S[n]$ :

$$
\frac{1}{\Delta F}=\frac{1}{c}+\frac{K_{d}}{c[S[n]]}
$$

where $c$ is a constant. As can be seen from Figure $3 \mathrm{~b}$, the plots of $1 / \Delta F$ versus [S[n]] shows linear relationships, indicating that $\mathrm{S}[\mathrm{n}](\mathrm{n}=6$ and 8) forms a 1:1 complex with Rh800. The dissociation constants are determined to be $9.5 \mu \mathrm{M}$ and $2.2 \mu \mathrm{M}$ for the Rh800 complex with $\mathrm{S}[6]$ and $\mathrm{S}[8]$, respectively. This result shows that the binding affinity of $\mathrm{Rh} 800$ to $\mathrm{S}[8]$ is about four-times larger than that of Rh800 to $\mathrm{S}[6]$. In the case of $\mathrm{S}[4]$, the binding affinity of Rh800 to $\mathrm{S}[4]$ is very low to determine the dissociation constant.

Figure 2. Fluorescence spectra of Rh800 (a) and ICG (b) upon adding S[8] in PBS. The concentration of Rh800 and ICG was $40 \mathrm{nM}$. Excitation wavelengths were set to $600 \mathrm{~nm}$ for Rh800 and $725 \mathrm{~nm}$ for ICG. [S[8]] $=0 \mu \mathrm{M}$ (blue line), $1.7 \mu \mathrm{M}$ (green line), $5.0 \mu \mathrm{M}$ (yellow line), $11.5 \mu \mathrm{M}$ (orange line), $24 \mu \mathrm{M}$ (red line), and $52 \mu \mathrm{M}$ (brown line).
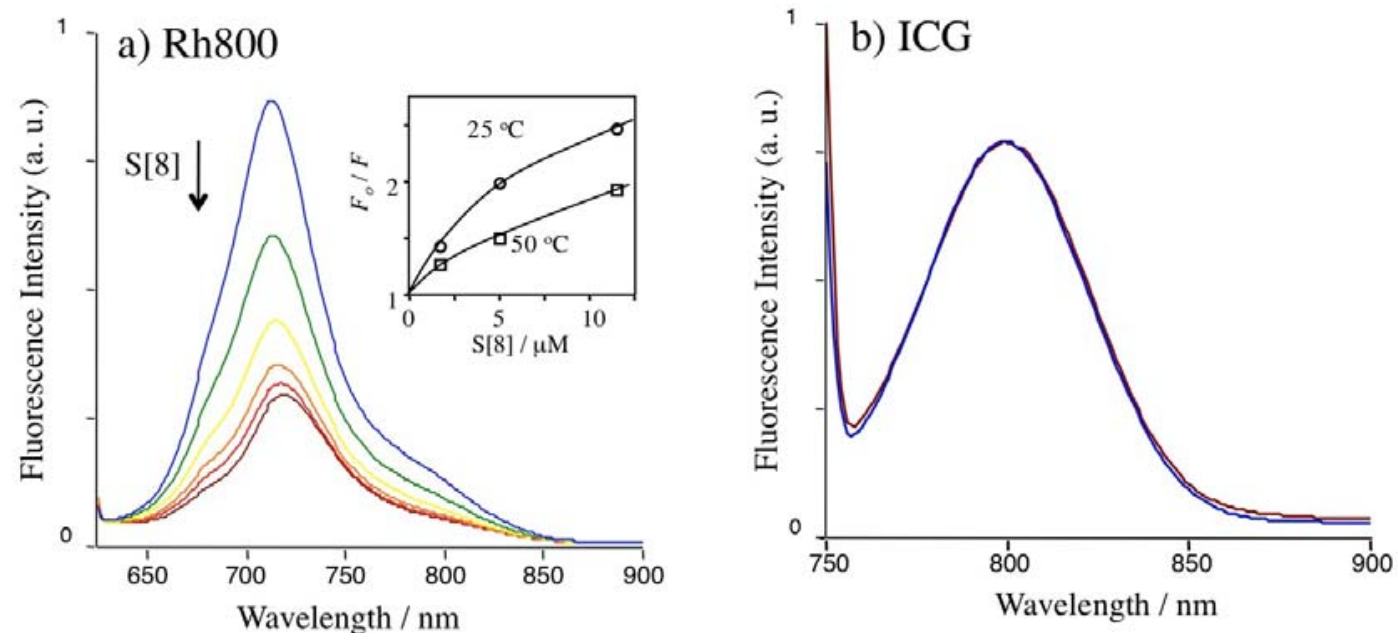

Figure 3. (a) Relative fluorescence intensity of $\mathrm{Rh} 800$ (40 $\mathrm{nM}$ in PBS) in the presence of $\mathrm{S}[\mathrm{n}] . \mathrm{S}[\mathrm{n}](1 \mathrm{mM})$ was added to the aqueous solution of $\mathrm{Rh} 800(40 \mathrm{nM})$ under stirring. (b) Plots of $1 / \Delta \mathrm{F}$ versus $1 /[S[\mathrm{n}]]$.
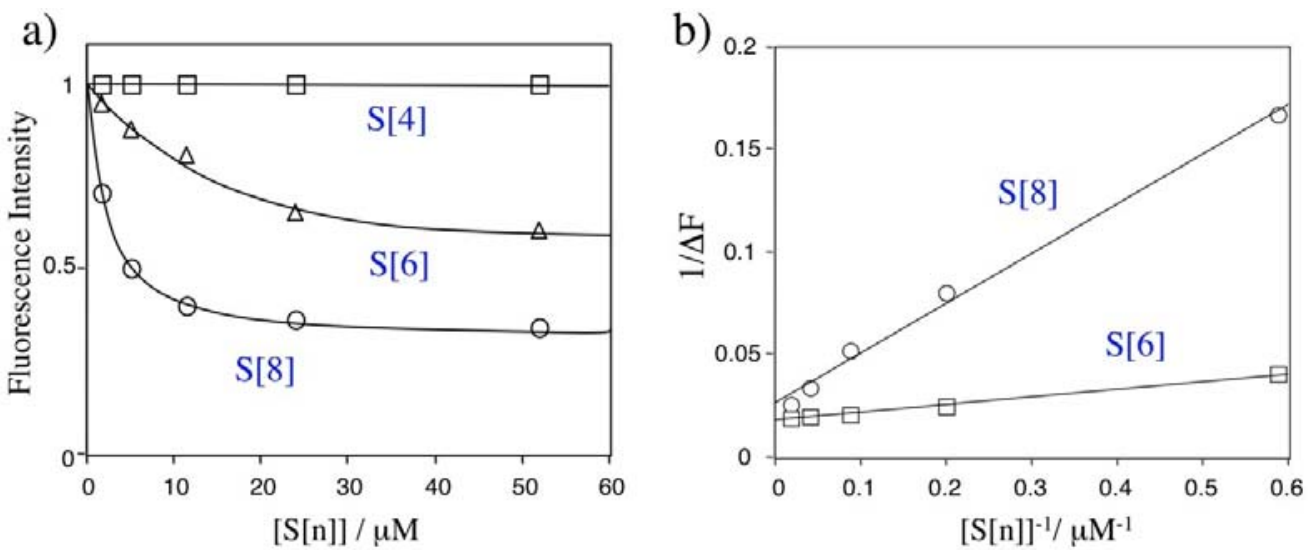


\subsection{Fluorescence Detection of ACh Using Rh800-S[8] Complex}

Figure 4a shows the fluorescence change of Rh800 in the aqueous solution of Rh800-S[8] complex upon adding ACh. The fluorescence intensity of Rh800 significantly increased with increasing ACh concentration. The inset shows the dependence of the relative fluorescence intensity of Rh800 at 710 $\mathrm{nm}$ on the ACh concentration. This result shows that the fluorescence changes in the Rh800-S[8] complex solution can be used for the detection of ACh in aqueous solution. The increase in the fluorescence intensity of Rh800 is explained by the competitive displacement of Rh800 by ACh:

$$
[R h 800-S[8]]+n \cdot A C h \quad \rightarrow \quad[n \cdot A C h-S[8]]+R h 800
$$

In the presence of excess amounts (500 equiv.) of ACh over Rh800, the intensity of Rh800 increased by a factor of $87 \%$. The inset graph indicates that the detection limit $(10 \%$ fluorescence change) of ACh is circa $5 \times 10^{-4} \mathrm{M}$. In the competitive replacement reaction, the dissociation constant ( $\left.K_{R h 800}\right)$ for the Rh800-S[8] complex can be rationalized to the dissociation constant $\left(K_{A C h}\right)$ for the ACh-S[8] complex as follows:

$$
\frac{\alpha([S[8]]-(1-\alpha)[R h 800]}{(1-\alpha) K_{R h 800}}=\frac{[A C h]^{n}}{K_{A C h}}, \quad \alpha=\frac{\left(F-F_{o}\right)}{\left(F_{\infty}-F_{o}\right)}
$$

where $F_{o}, F$, and $F_{\infty}$ are the fluorescence intensity of the $\mathrm{Rh} 800$ before, during, and after the titration with ACh in large excess amounts. Figure $4 \mathrm{~b}$ shows plots of $f\left(=\alpha([S[8]]-(1-\alpha)[R h 800]) /(1-\alpha) K_{R h 800}\right)$ versus $[\mathrm{ACh}]$ or $[\mathrm{ACh}]^{2}$. When $n$ is set to 1 , the plot shows a linear relationship, indicating that one ACh molecule is replaced by one Rh800 molecule in the Rh800-S[8] complex. From the slope of the plot, the value of $K_{A C h}$ for the ACh-S[8] complex is determined to be $1.7 \mathrm{mM}$.

Figure 4. (a) Fluorescence spectra of the aqueous solution of Rh800-S[8] complex upon adding ACh. $[\mathrm{Rh} 800]=40 \mathrm{nM},[\mathrm{S}[8]] /[\mathrm{Rh} 800]=800$, and $[\mathrm{ACh}]:$ a) $0 \mathrm{mM}$, b) $1.1 \mathrm{mM}$, c) $3.4 \mathrm{mM}$, d) $7.7 \mathrm{mM}$, e) $12 \mathrm{mM}$, and f) $16 \mathrm{mM}$. Inset shows concentration dependence of $\mathrm{ACh}$ on the fluorescence intensity of Rh800. (b) Plots of $f$ versus [ACh] and $f$ versus $[\mathrm{ACh}]^{2}$.
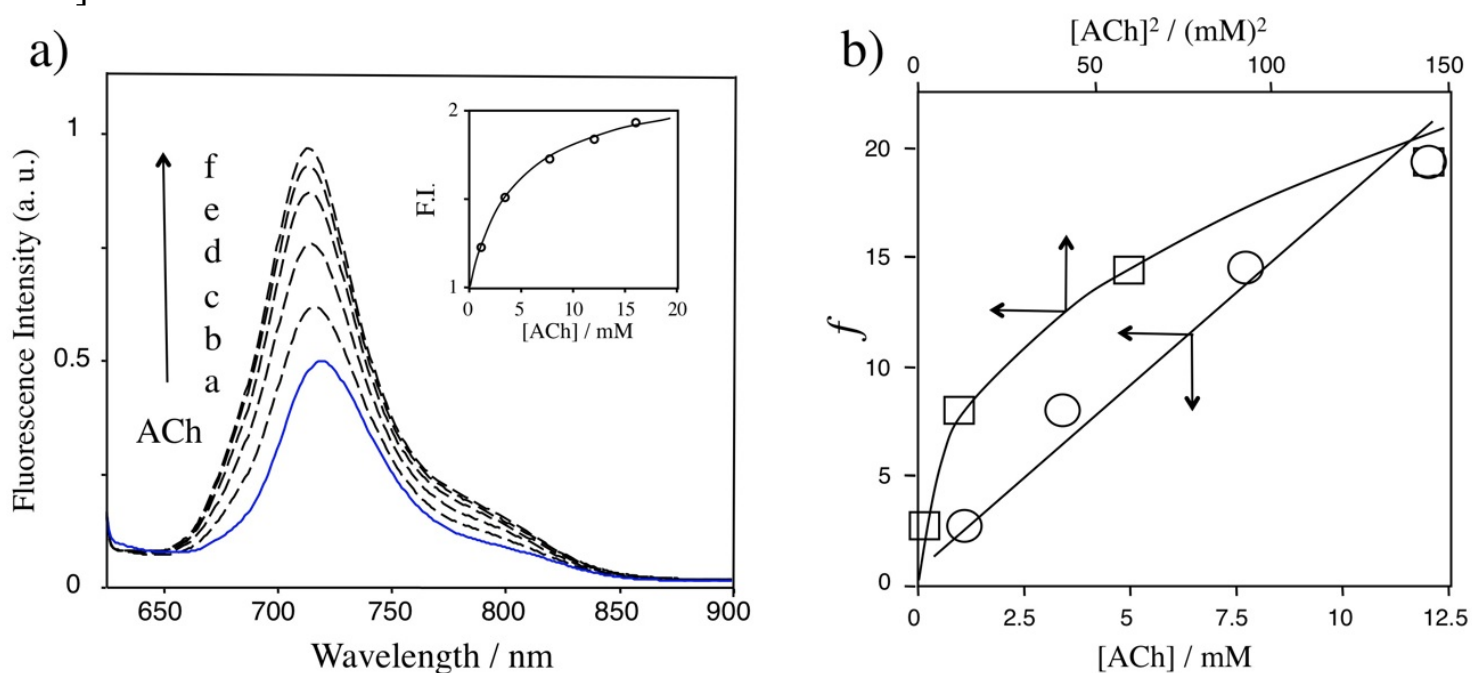


\subsection{Detection Selectivity of Rh800-S[8] Complex}

To check the detection selectivity of the Rh800-S[8] complex, we first examined the effects of ACh, dopamine, and GABA on the fluorescence intensity of the Rh800-S[8] complex. Dopamine is one of monoamine neurotransmitters that have cation charges similar to ACh [35]. GABA ( $\gamma$-aminobutyric acid) is the chief inhibitory neurotransmitter in the central nerve system [36]. GABA is a kind of amino acids with no net charge. We measured the time course of the fluorescence intensity of the Rh800-S[8] solution upon addition of ACh, dopamine, and GABA. The fluorescence intensity of $\mathrm{Rh} 800$ responded to the successive additions of $\mathrm{ACh}$ as shown in Figure 5a. In contrast, the addition of dopamine and GABA up to $7.7 \mathrm{mM}$ did not change the fluorescence intensity of Rh800 (Figure $5 \mathrm{~b}$ and 5c). The effect of $\mathrm{ACh}$ on the $\mathrm{Rh} 800$ fluorescence was also examined in the presence of $5.5 \mathrm{mM}$ of dopamine. As shown in Figure 5d, the fluorescence response of Rh800 for ACh was not hampered by dopamine. These results show that the fluorescence response of Rh800-S[8] complex is sensitive to ACh compared to dopamine and GABA.

Figure 5. Time course of the fluorescence intensity of Rh800-S[8] solution upon adding (a) $\mathrm{ACh}$, (b) dopamine, and (c) GABA. (d) Changes in the fluorescence intensity of the Rh800$\mathrm{S}[8]$ solution by successive addition of dopamine and ACh. Aliquots of the neurotransmitters (350 $\mathrm{mM}$ ) were added to the Rh800-S[8] solution. Fluorescence intensity was measured at $710 \mathrm{~nm}$ with excitation at $600 \mathrm{~nm}$. [Rh800] $=40 \mathrm{nM},[\mathrm{S}[8]] /[\mathrm{Rh} 800]=800$.
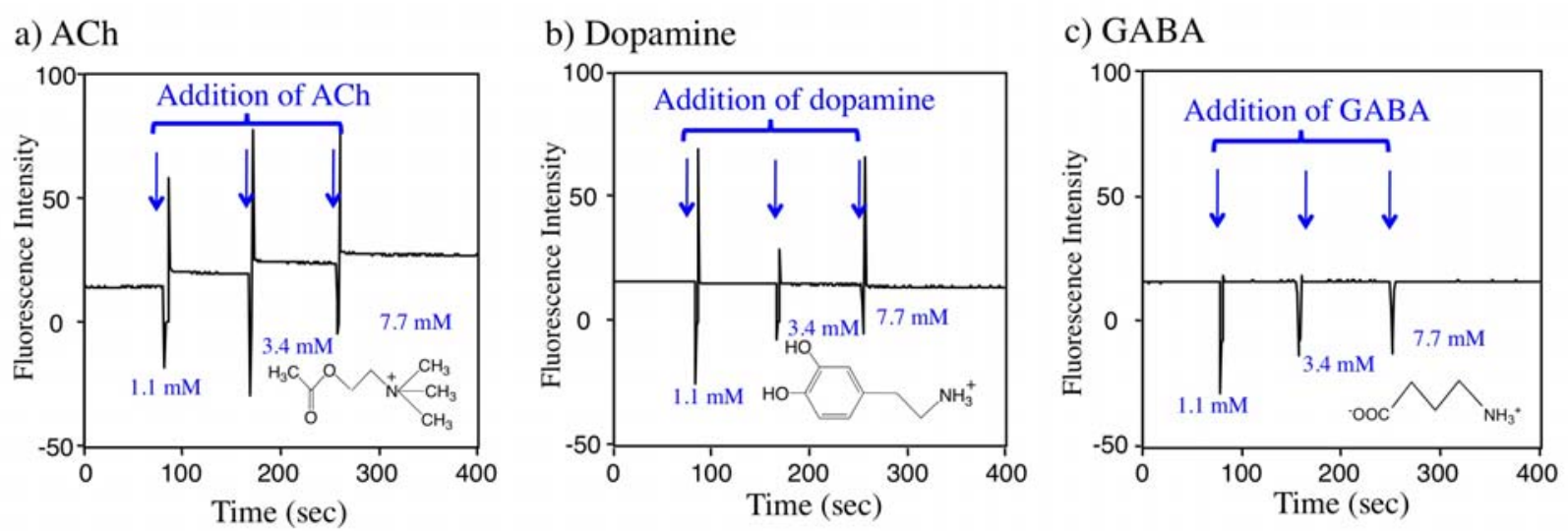

d) Dopamine/ACh

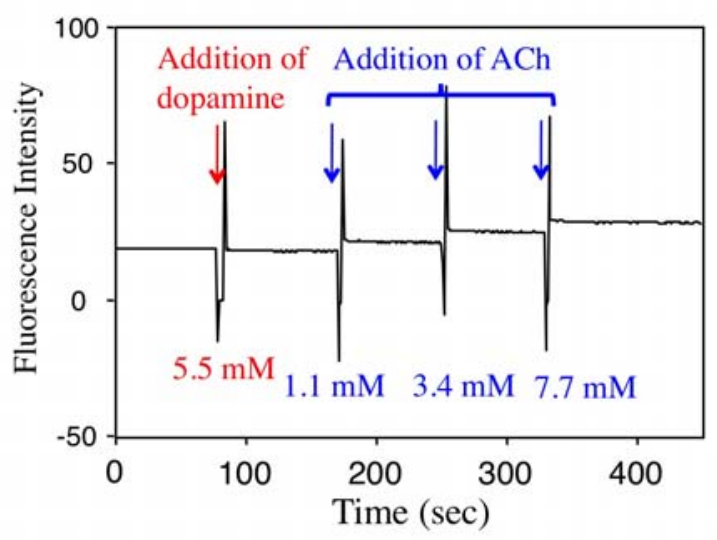


We further examined fluorescence responses of the Rh800-S[8] complex for other neurotransmitters (glysine and L-asparatic acid), basic amino acids, ammonium chloride, and choline. The results including ACh, dopamine, and GABA are summarized in Figure 6. Among the neurotransmitters examined, ACh was most sensitive to change in the fluorescence intensity of Rh800. In the presence of $\mathrm{ACh}$, the fluorescence intensity was increased by a factor of $87 \%$. Choline also increased the fluorescence intensity by a factor of $70 \%$. Other neurotransmitters such as dopamine, GABA, glycine, and $L$-asparatic acid scarcely affected the fluorescence intensity of Rh800-S[8] solution. Basic amino acids with cationic charges ( $L$-histidine and $L$-lysine) slightly increased the fluorescence intensity of the Rh800-S[8] solution, while ammonium chloride did not affect its fluorescence intensity. These results indicate that hydrophobic interaction and electrostatic interaction play important roles in the formation of complex between S[8] and ACh. The strong binding ability of S[8] for choline implies that the quaternary ammonium moieties of $\mathrm{ACh}$ and choline are recognized by the $\pi$-basic cavity $[16,20,23]$ of $\mathrm{S}[8]$.

In the view of biological application, the detection selectivity of ACh over choline is very important because ACh is rapidly hydrolyzed to choline and acetic acids by acetylcholineesterase in vivo. Unfortunately, the Rh800-S[8] complex cannot distinguish between ACh and choline. Thus, for using $\mathrm{Rh} 800-\mathrm{S}[8]$ complex as a fluorescent ACh probe in biological samples, it would be necessary to perform microwave deactivation [37] of acetylcholineesterase to prevent the hydrolysis of ACh.

Figure 6. Fluorescence changes $(\Delta F$ at $710 \mathrm{~nm})$ in $\mathrm{Rh} 800-\mathrm{S}[8]$ solution upon adding $\mathrm{ACh}$, other neurotransmitters (dopamine, GABA, glysine, L-asparatic acid), basic amino acids (L-histidine, L-lysine), ammonium chloride, and choline. $100 \mu \mathrm{L}$ of these chemicals (350 $\mathrm{mM}$ in water) was added to the Rh800-S[8] solution $(3 \mathrm{~mL})$, where $[\mathrm{Rh} 800]=40 \mathrm{nM}$ and $[\mathrm{S}[8]] /[\mathrm{Rh} 800]=800$.

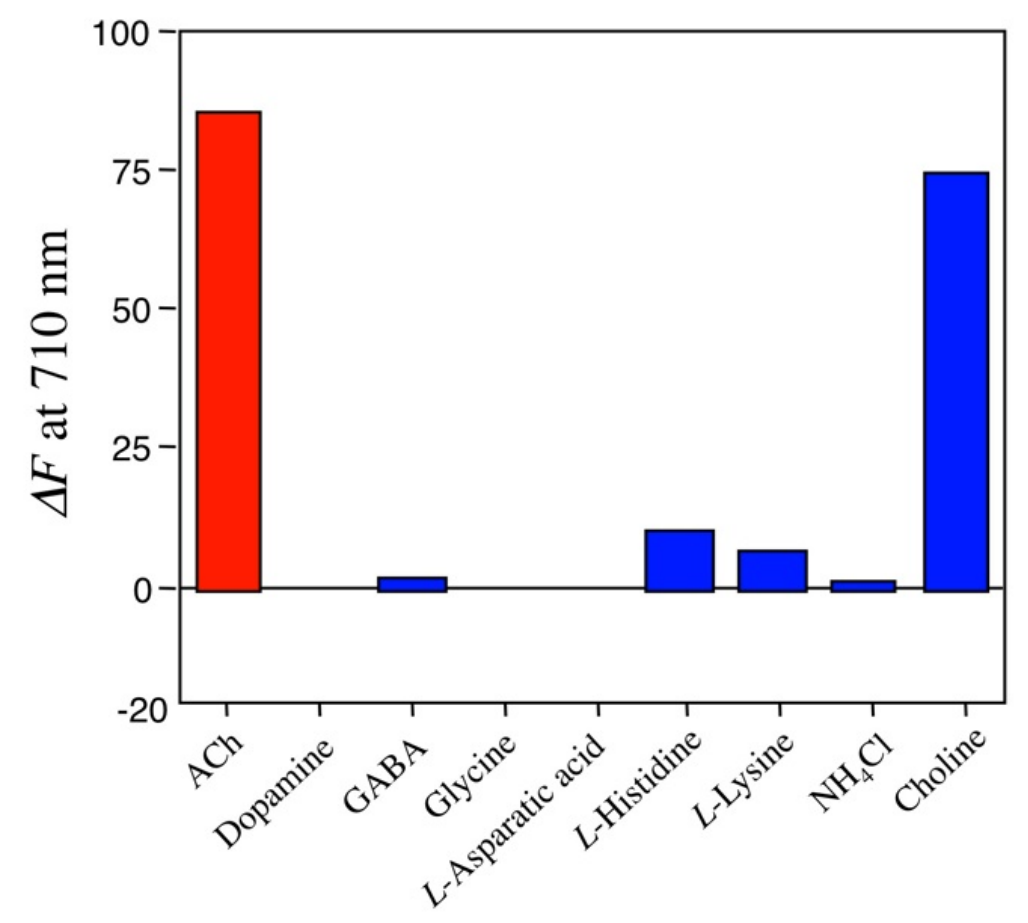




\section{Experimental Section}

\subsection{Materials}

p-Sulfonatocalix[4]arene (S[4]), p-sulfonatocalix[6]arene (S[6]), indocyanine greeen (ICG) were purchased from Tokyo Organic Chemicals (Japan). p-Sulfonatocalix[8]arene (S[8]) was purchased from Dojin Chemicals (Japan). Acetylcholine chloride, dopamine hydrochloride were purchase from Wako Chemicals (Japan). Rhodamine 800 (Rh800) was purchased from Anaspec. Other chemicals used are analytical grade.

\subsection{Fluorescence Spectra and Quantum Yield Measurements}

Fluorescence spectra were measured on a FP-6200 spectrofluorometer (Jasco) using a quarts cuvette $(1 \mathrm{~cm} \times 1 \mathrm{~cm} \times 4.5 \mathrm{~cm})$, where excitation wavelength was set to $610 \mathrm{~nm}$ for Rh800 and $725 \mathrm{~nm}$ for ICG. Emission efficiencies of NIR-dyes in PBS were evaluated by using an absolute quantum yield measurement system (C10027, Hamamatsu Photonic). The absolute quantum yield (QY) is defined as $Q Y=P N_{e m} / P N_{a b}$, where $P N_{e m}$ and $P N_{a b}$ are the number of emitted and absorbed photons by fluorescence materials. Excitation wavelengths were set to $610 \mathrm{~nm}$ for Rh800and $725 \mathrm{~nm}$ for ICG. The concentration of the NIR dyes was $1 \mu \mathrm{M}$.

\subsection{Fluorescence Titration of NIR Dyes by S[n]}

Rh800 and ICG were dissolved in PBS and their concentrations were set to $40 \mathrm{nM}$. To $3 \mathrm{~mL}$ of the NIR-dye solution, microliter aliquots of aqueous solution $\mathrm{f} \mathrm{S}[\mathrm{n}](1 \mathrm{mM})$ were added under stirring. After stirring for $2 \mathrm{~min}$, fluorescence spectra of the NIR dye were measured.

\subsection{Competitive Fluorophore Displacement by ACh in the Complex of R800-S[n]}

To $3 \mathrm{~mL}$ of Rh800 solution (40 nM/PBS), $100 \mu \mathrm{L}$ of $\mathrm{S}[\mathrm{n}](1 \mathrm{mM})$ was added. To this solution, microliter aliquots of $\mathrm{ACh}(350 \mathrm{mM})$ were added under stirring. After 2 min stirring, fluorescence spectra were measured. For the competitive fluorophore displacement by other neurotransmitters, amino acids, ammonium chloride, and choline, similar procedure as the above method was applied.

\section{Conclusions}

In conclusion, we have developed a new ACh detection method using NIR fluorescence of the Rh800-S[8] complex. The competitive fluorophore displacement by ACh in the Rh800-S[8] complex caused significant increase in the NIR fluorescence intensity of Rh800. The detection limit of ACh in this method was about $5 \times 10^{-4} \mathrm{M}$. Fluorescence response of the Rh800-S[8] complex was highly specific to ACh over other neurotransmitters such as dopamine, GABA, glysine, and $L$-asparatic acid. Using the Rh800-S[8] complex as a fluorescent probe, ACh could be detected by NIR-fluorescence at $710 \mathrm{~nm}$. To the best of our knowledge, this is a first report of a NIR-fluorescence detection of ACh in aqueous solution. Unfortunately, our NIR detection system cannot discriminate ACh and choline, because $p$-sulfonatocalix[8]arene has poor binding selectivity for ACh over choline. In addition, the detection limit $\left(5 \times 10^{-4} \mathrm{M}\right)$ of $\mathrm{ACh}$ is not enough to measure ACh concentration in biological samples. 
Thus, for practical application of our ACh detection method for biological systems, detection selectivity and sensitivity for ACh should be improved.

\section{Acknowledgements}

This work was partly supported by the Ministry of Education, Science, Sport, and Culture of Japan (Grant-in-Aid for Scientific Research, No. 19550157).

\section{References and Notes}

1. Augustine, G.J.; Fritzpatrick, D.; Hall, W.C.; LaMantia, A.-S.; MaNamara, J.O.; Mooney, R.D.; Platt, M.L.; Purves, D.; Simon, S.A.; White, L.E.; Williams, S.M.; Winstein, S.; Henderson, R.B. NeuroScienec; Purves, D., Augustine, G.J., Fritzpatrick, D., Hall, W.C., LaMantia, A.-S., MaNamara, J.O., White, L.E., Ed.; Sinauer: Sunderland, MA, USA, 2008; Chapter 6, pp. 119-126.

2. Albert, B.; Johnson, A.; Lewis, J.; Laff, M.; Roberts, K.; Walter, P. Molecular Biology of the Cell, 5th ed.; Garland Science: New York, NY, USA, 2008; Chapter 15, p. 882.

3. Honda, K.; Kunihara, M.; Maruyama, Y. Determination of picomole amounts of choline and acetylcholine in blood by gas chromatography-mass spectrometry equipped with a newly improved pyrolyzer. J. Chromatogr. A 1982, 239, 335-342.

4. Honda, K.; Miyaguchi, K.; Nishino, H.; Tanaka, H.; Yao, T.; Imai, K. High-performance liquid chromatography followed by chemiluminescence detection of acetylcholine and choline utilizing immobilized enzymes. Anal. Biochem. 1986, 153, 50-53.

5. Ricny, J.; Coupek, J.; Tucek, S. Determination of acetylcholine and choline by flow injection with immobilized enzymes and fluorometric or luminometric detection. Anal. Biochem. 1989, 170, 221-227.

6. Hestrin, S. The reaction of acetylcholine and other carboxylic acid derivatives with hydroxylamine, and its analytical application. J. Biol. Chem.1949, 180, 249-261.

7. Schuberth, J.; Sparf, B.; Sundwall, A. A technique for the study of acetylcholine turnover in mouse brain in vivo. J. Neurochem. 1969, 16, 695-700.

8. Feigenson, M.E.; Saeleus, J.K. An enzyme assay for acetylcholine. Biochem. Pharmacol. 1969, 18, 1479-1486.

9. Snejdarkova, M.; Svobodova, L.; Evtugyn, G.; Budnikov, H.; Karyakin, A.; Nikolelis, D.P.; Hianik, T. Acetylcholineesterase sensors based on gold electrodes modified with dendrimer and polyaniline A comparative research. Anal. Chem. Acta. 2004, 514, 79-88.

10. Shibli, S.M.A.; Beenakumari, K.S.; Suma, N.D. Nano nickel oxide/nickel incorporated nickel composite coating for sensing and estimation of acetylcholine. Biosens. Bioelectron. 2006, 22, 633-638.

11. Lakowicz, J.R. In Principles of Fluorescence Spectroscopy, 3rd ed.; Springer: New York, NY, USA, 2006; Chapter 23, p. 623-674.

12. Weissleder, R.A. A clearer vision for in vivo imaging. Nat. Biotechnol. 2001, 19, 316-317.

13. Liu, H.; Beauvoit, B.; Kimura, M.; Chance, B. Dependence of tissue optical properties on soluteinduced changes in refractive index and osmolarity. J. Biomed. Opt. 1996, 1, 200-211. 
14. Lim, Y.T.; Kim, S.; Nakayama, A.; Stott, N.E.; Bawendi, M.G.; Frangioni, J.V. Selection of quantum dot wavelengths for biomedical assays and imaging. Mol. Imaging 2003, 2, 50-64.

15. Shinkai, S.; Araki, K.; Manabe, O. NMR determination of association constants for calixarene complexes. Evidence for the formation of a 1:2 complex with calix[8]arene. J. Am. Chem. Soc. 1988, 110, 7214-7215.

16. Shinkai, S.; Araki, K.; Matsuda, T.; Nishiyama, N.; Ikeda, H.; Takasu, I.; Iwamoto, M. NMR and crystallographic studies of a $p$-sulfonatocalix[4]arene-guest complex. J. Am. Chem. Soc. 1990, 112, 9053-9058.

17. Arena, G.; Casnati, A.; Contino, A.; Gulino, F.G.; Sciotto, D.; Ungaro, R. Entropic origin of the sulfonate groups' electrostatic assistance in the complexation of quaternary ammonium cations by water soluble calix[4]arenes. J. Chem. Soc. Perkin Trans. 2000, 2, 419-423.

18. Aruduini, A.; Demuru, D.; Pochini, A.; Secchi, A. Recognition of quaternary ammonium cations by calix[4]arene derivatives supported on gold nanoparticles. Chem. Commun. 2005, 5, 645-647.

19. Wang, L.-H.; Guo, D.-S.; Chen, Y.; Liu, Y. Thermodynamics of interactions between organic ammonium ions and sulfonatocalixarenes. Thermoch. Acta 2006, 443, 132-135.

20. Lehn, J.-M.; Meric, R.; Vigneron, J.-P.; Cerario, M.; Guilhem, J.; Pascard, C.; Asfari, Z.; Vicens, $\mathrm{J}$. Binding of acetylcholine and other quaternary ammonium cations by sulfonated calixarenes. Crystal structure of a [choline-tetrasulfonated calix[4]arene] complex. Supramol. Chem. 1995, 5, 97-103.

21. Koh, K.N.; Araki, K.; Ikeda, A.; Otsuka, H.; Shinkai, S. Reinvestigation of calixarene-based artificial-signaling acetylcholine receptors useful in neutral aqueous (water-methanol) solution. $J$. Am. Chem. Soc. 1996, 118, 755-758.

22. Zhang, Y.-J.; Cao, W.-X.; Xu, J. Interaction of sulfonated calix[n]arenes with rhodamine B and its application to determine acetylcholine in a real neutral aqueous medium. Chin. J. Chem. 2002, 20, 322-326.

23. Jin, T. A new fluorometric method for the detection of the neurotransmitter acetylcholine in water using a dansylcholine complex with $p$-sulfonated calix[8]arene. J. Inclusion Phenom. Macrocyclic Chem. 2003, 45, 195-201.

24. Wang, L.-H.; Guo, D.-S.; Chen, Y.; Liu, Y. Thermodynamics of interactions between organic ammonium ions and sulfonatocalixarenes. Thermoch. Acta 2006, 443, 132-135.

25. Bakirci, H.; Nau, W.M. Fluorescence regenerations as a signaling principle for choline and carnitine binding: a refined supramolecular sensor system based on a fluorescent azoalkane. Adv. Funct. Mater. 2006, 16, 237-242.

26. Korbakov, N.; Timmerman, P.; Lidich, N.; Urbach, B.; Sa'ar, A.; Yitzchaik, S. Acetylcholine detection at micromolar concentrations with the use of an artificial receptor-based fluorescence switch. Langmuir 2008, 24, 2580-2587.

27. Jin, T.; Fujii, F.; Ooi, Y. Interfacial recognition of acetylcholine by an amphiphilc $p$-sulfonatocalix[8]arene derivative incorporated into dimyristoyl phosphatidylcholine vesicles. Sensors 2008, 8, 6777-6790.

28. Rizvi, N.H.; Opalinska, M.M.; French, P.M.W.; Taylor, J.R. A cw rhodamine 800 dye laser passively mode-locked with neocyanine. Opt. Commun. 1990, 80, 57-59. 
29. Jilkina, O.; Kong, H.-J.; Hwi, L.; Kuzio, B.; Xiang, B.; Manley, D.; Jackson, M. Kupriyanov, V.V. Interaction of a mitochondrial membrane potential-sensitive dye, rhodamine 800, with rat mitochondria, cells, and perfused hearts. J. biomed. Opt. 2006, 11, 014009(1)-014009(9).

30. Benson, R.C.; Kues, H.A. Fluorescence properties of indocyanine green as related to angiography. Phys. Med. Biol. 1978, 23, 159-163.

31. Saxena, V.; Sadoqi, M.; Shao, J. Degradation kinetics of indocyanine green in aqueous solution. $J$. Pharm. Sci. 2003, 92, 2090-2097.

32. Lee, H.; Berezin, M.Y.; Henary, M.; Strekowski, L.; Achiefu, S. Fluorescence lifetime properties of near-infrared cyanine dyes in relation to their structures. J. Photochem. Photobiol. A: Chem. 2008, 200, 438-444.

33. Abugo, O.O.; Nair, R.; Lakowicz, J.R. Fluorescence properties of rhodamine 800 in whole blood and plazma. Anal. Biochem. 2000, 279, 142-150.

34. Lakowicz, J.R. Principles of Fluorescence Spectroscopy, 3rd ed.; Springer: New York, NY, USA, 2006; Chapter 8, pp. 278-282.

35. Augustine, G.J.; Fritzpatrick, D.; Hall, W.C.; LaMantia, A.-S.; MaNamara, J.O.; Mooney, R.D.; Platt, M.L.; Purves, D.; Simon, S.A.; White, L.E.; Williams, S.M.; Winstein, S.; Henderson, R.B. NeuroScienec; Purves, D., Augustine, G.J., Fritzpatrick, D., Hall, W.C., LaMantia, A.-S., MaNamara, J.O., White, L.E., Ed.; Sinauer: Sunderland, MA, USA, 2008; Chapter 6, pp. 137-138.

36. Augustine, G.J.; Fritzpatrick, D.; Hall, W.C.; LaMantia, A.-S.; MaNamara, J.O.; Mooney, R.D.; Platt, M.L.; Purves, D.; Simon, S.A.; White, L.E.; Williams, S.M. Winstein, S.; Henderson, R.B. NeuroScienec; Purves, D., Augustine, G.J., Fritzpatrick, D., Hall, W.C., LaMantia, A.-S., MaNamara, J.O., White, L.E., Ed.; Sinauer: Sunderland, MA, USA, 2008; Chapter 6, p. 120 and pp. 132-137.

37. Barnes, N.M.; Costall, B.; Fell, A.F.; Naylor, R. An HPLC assay procedure of sensitivity and stability for measurement of acetylcholine and choline in neuronal tissue. J. Pharm. Pharmacol. 1987, 39, 727-731.

(C) 2010 by the authors; licensee Molecular Diversity Preservation International, Basel, Switzerland. This article is an open-access article distributed under the terms and conditions of the Creative Commons Attribution license (http://creativecommons.org/licenses/1by/3.0/). 